\title{
Subacute thyroiditis following influenza vaccine: a case report and literature review
}

\author{
Munther S. Momani, Ayman A. Zayed, Faris G. Bakri \\ Internal Medicine Department, The Hospital of the University of Jordan, Amman, Jordan
}

\begin{abstract}
Subacute thyroiditis following influenza vaccination is a rarely reported condition. Here, we review this condition and report the case of a 40-year-old male who developed subacute thyroiditis following the administration of an influenza vaccine containing the (H1N1) pandemic 2009 strain. Interestingly, the patient had history of pericarditis and his HLA typing showed HLA B35. Physicians should be aware of this complication for influenza vaccine and of the relationship of HLA B35 haplotype with the susceptibility to subacute thyroiditis and other autoimmune disorders.
\end{abstract}

\section{Introduction}

The influenza vaccine has been considered generally safe with very few complications. Rare reports have described the association of influenza vaccine with different autoimmune complications such as vasculitis, ${ }^{1,2}$ encephalomyelitis, ${ }^{3-5}$ Guillain-Barre syndrome, ${ }^{5}$ giant cell arteritis, acute myocarditis, uveitis, myositis, and erythema multiforme. ${ }^{6}$

Subacute thyroiditis (SAT) is an inflammatory disorder that usually occurs after viral infections. Here, we review the literature and report a case of SAT in a healthcare worker after the administration of an influenza vaccine that contained the (H1N1) pdm09 strain. This is a rarely reported condition and according to our knowledge, has only been described in four

Correspondence: Munther S. Momani, Internal Medicine Department, Hospital of the University of Jordan, Queen Rania Street, Amman, Jordan.

Tel.: +962797053267 .

E-mail: munthermomani1971@gmail.com

Key words: Subacute painful thyroiditis; influenza vaccine; thyrotoxicosis.

Conflict of interest: the authors declare no potential conflict of interest.

Received for publication: 2 September 2014.

Revision received: 3 October 2014.

Accepted for publication: 3 October 2014.

This work is licensed under a Creative Commons Attribution NonCommercial 3.0 License (CC BY-NC 3.0).

CCopyright M.S. Momani et al., 2015

Licensee PAGEPress, Italy

Italian Journal of Medicine 2015; 9:384-386

doi:10.4081/itjm.2015.542 case reports..$^{7-10}$ However, it is possible that the diagnosis of SAT might have been missed in many patients following vaccination since the symptoms of neck pain and fever are also well-recognized side effects of the influenza vaccine. ${ }^{8}$

\section{Case Report}

In December 2012, a 40-year-old healthy male presented to our clinic with neck pain. Five weeks prior to his presentation, the patient received the seasonal influenza vaccine [Agrippal S1; batch number 127301, Novartis, Sovicille, Italy, containing the following strains: A/California/7/2009 (H1N1) pdm09; A/Victoria/361/2011 (H3N2); and B/Wisconsin/1/2010], and at the time of vaccination, the patient had no symptoms of upper respiratory tract infection and was feeling well. However, two days following the vaccination, the patient developed mild fatigue, myalgia, and fever. These symptoms lasted for three days and resolved spontaneously. Nine days later (and two weeks after receiving the vaccine), the patient started to complain of neck pain in the anterior and left side of the neck that increased upon swallowing solids and was associated with attacks of fever. He also had episodes of shortness of breath and palpitations occurring with moderate exertion and occasionally at rest. Two weeks after the onset of neck pain, the patient began to use oral diclofenac with marked improvement. Subsequently, the patient presented to us after three weeks from the onset of the neck pain. The patient worked as a physician and had received the seasonal influenza vaccine in the previous fall seasons (2010 and 2011) without complications. Seven years ago, he had an episode of pericarditis that was not vaccine related and resolved with nonsteroidal anti-inflammatory drug therapy. He had no family history of thyroid disease.

Upon physical examination, the patient was afebrile. His heart rate was $90 / \mathrm{min}$ and regular. Thy- 
roid examination revealed a minimally enlarged thyroid on the left side with tenderness to light touch. He had no eye proptosis, no lid lag, and no lid retraction. He had regular heart sounds and a normal lung exam.

His laboratory tests showed a hemoglobin level of $12.5 \mathrm{mg} / \mathrm{dL}$, a white blood cell (WBC) count of $8000 / \mathrm{mL}$, and a platelet count of $315,000 / \mathrm{mL}$. His Creactive protein (CRP) was elevated at $41.9 \mathrm{mg} / \mathrm{L}$ (normal, $<5$ ) and his erythrocyte sedimentation rate (ESR) was $55 \mathrm{~mm} / \mathrm{h}$. His kidney and liver functions were normal. The electrocardiogram was normal. His thyroid-stimulating hormone (TSH) level was 0.055 $\mathrm{mIU} / \mathrm{L}$ (normal, 0.5-5), free thyroxine (free T4) level was $30 \mathrm{pmol} / \mathrm{L}$ (normal, 9-19), and free triiodothyronine (free T3) level was $5.1 \mathrm{pmol} / \mathrm{L}$ (normal, 2.365.69). Tests for thyroid autoimmune antibodies (thyroperoxidase and thyroglobulin) were both negative. An ultrasound examination of the thyroid gland showed the organ to be moderately enlarged with a lobulated left lobe without focal lesions and a normal sized right lobe. The thyroid Technetium-99mpertechnetate scan and uptake showed a faintly visualized thyroid gland with a very low tracer uptake of $0.06 \%$ (normal, $2-4 \%$ ), which is consistent with the diagnosis of thyroiditis (Figure 1).

Subsequently, the patient was started on propranolol for symptomatic relief and continued on diclofenac 50 $\mathrm{mg}$ twice daily with sufficient pain relief. Three weeks later, the patient discontinued both medications as the neck pain and the palpitations had ceased.

Four weeks after the presentation of the patient, repeated laboratory tests showed a TSH level of 1.857 $\mathrm{mU} / \mathrm{L}(0.5-5.0)$, a free T4 level of 9.66 Pmol/L (9-19), a free T3 level of 3.5 Pmol/L (2.36-5.69), a hemoglobin level of $14.7 \mathrm{mg} / \mathrm{dL}$, a WBC count of $7600 / \mathrm{mL}$, and a platelet count of $294,000 / \mathrm{mL}$. CRP decreased to $1.59 \mathrm{mg} / \mathrm{L}$, and ESR decreased to $10 \mathrm{~mm} / \mathrm{h}$. Eight weeks after presentation, the thyroid function tests returned to normal values with a TSH level of 3.03 $\mathrm{mU} / \mathrm{L}$, a free T4 level of $13.53 \mathrm{Pmol} / \mathrm{L}$, and a free T3 level of $3.03 \mathrm{Pmol} / \mathrm{L}$. HLA typing for the A and B types performed by cytotoxic cross match and for the DR type by polymerase chain reaction revealed A2/A24, B57/B35, DR17/DR17, DR 52/DR52, and DQ2/DQ2 haplotypes. The patient remained asymptomatic and did not develop hypothyroid phase. At a one-year follow-up, the patient was still clinically and biochemically euthyroid.

\section{Discussion}

SAT is a self-limited inflammatory disorder that presents with a prodromal phase of fever and thyroid pain. Thyrotoxicosis then develops followed by a hypothyroid state with an eventual return to normal thyroid function. SAT has been associated with several viral infections including influenza virus, Coxsackie virus, cytomegalovirus, Epstein-Barr virus, aden- ovirus, human immunodeficiency virus, echoviruses, mumps, and measles. ${ }^{11}$ The pathogenesis of virus-associated disease has been proposed to be cytotoxic Tcell recognition of a complex of virus and cell antigens, which leads to thyroid damage. ${ }^{12,13}$

Here, we document the development of SAT after influenza vaccination in an adult patient who presented with neck pain and fever. We highly suspect that this episode of SAT was directly associated with the influenza vaccine as the episode occurred immediately after influenza vaccination and in the absence of symptoms suggestive of viral infection.

Influenza vaccine causing SAT was reported in only four cases so $\mathrm{far}^{7-10}$ (Table 1).

All of these patients had uneventful recovery except one patient who developed dyserythropoiesis but eventually had made full recovery. Similarly, full recovery was also observed in the present case. Recurrent exposure to the vaccine, similar to the present case, was mentioned in two cases, this recurrent exposure might have resulted in immune system sensitization, which subsequently facilitated the development of SAT. ${ }^{10}$ The HLA type was also mentioned in two patients, and similar to the present case, those two patients had HLA B35 haplotype. HLA B35 has been associated with increased susceptibility to various viral infections and thus, the development of SAT. ${ }^{8,10}$ Therefore, in the present case, the history of pericarditis, the occurrence of SAT, and the presence of HLA B35 indicate a susceptibility to autoimmune disease.

The evidence for influenza infection in SAT comes mostly from few serological studies and observations; ${ }^{14}$ Volpe et al. ${ }^{15}$ found that patients with SAT who had no symptoms of viral disease had demonstrated increases

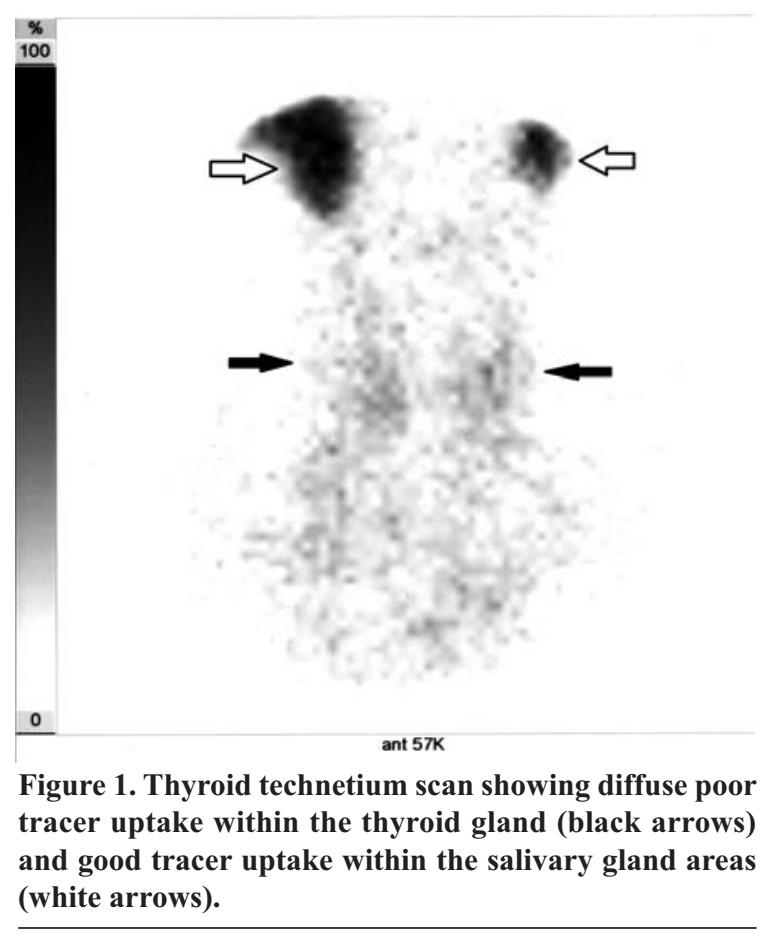


Table 1. Clinical characteristics of patients with subacute thyroiditis following influenza vaccination.

\begin{tabular}{|c|c|c|c|c|c|c|c|c|}
\hline Ref. & Gender & Age (y) & $\begin{array}{l}\text { Influenza } \\
\text { vaccine }\end{array}$ & $\begin{array}{c}\text { Previous } \\
\text { vaccination }\end{array}$ & HLA typing & Treatment & $\begin{array}{l}\text { Hypothyroid } \\
\text { phase }\end{array}$ & Outcome \\
\hline 7 & $\mathrm{~F}$ & 36 & H1N1 vaccine & NM & NM & $\begin{array}{l}\text { Steroids+ } \\
\text { propranolol }\end{array}$ & No & Full recovery \\
\hline 8 & $\mathrm{~F}$ & 49 & $\begin{array}{c}\text { Hemagglutinin } \\
\text { vaccine } \\
\text { (SEIKEN) } \\
\text { in Oct } 2009\end{array}$ & $\begin{array}{c}\text { In the previous } \\
\text { year }\end{array}$ & $\begin{array}{c}\text { A2/A11, B62/B35, } \\
\text { DR4/DR14 }\end{array}$ & Steroid & NM & Full recovery \\
\hline 9 & $\mathrm{~F}$ & 25 & $\begin{array}{c}\text { Vaccine } \\
\text { (Vaxigrip) in } 2009\end{array}$ & NM & NM & NSAID+steroid & NM & Full recovery \\
\hline 10 & M & 55 & $\begin{array}{c}\text { Live attenuated } \\
\text { vaccine (Fluvirin) }\end{array}$ & Once in 2006 & B35 & None & Yes & $\begin{array}{l}\text { Dyserythropoiesis } \\
\text { but eventual } \\
\text { recovery }\end{array}$ \\
\hline $\begin{array}{l}\text { Present } \\
\text { case }\end{array}$ & M & 40 & $\begin{array}{l}\text { Vaccine (Agrippal) } \\
\text { in Dec } 2012\end{array}$ & $\begin{array}{l}\text { Annually in the } \\
\text { previous } 2 \text { years }\end{array}$ & $\begin{array}{c}\text { A2 /A24, B57/35, } \\
\text { B57/B35, } \\
\text { DR17/DR17, } \\
\text { DR 52/DR52, and } \\
\text { DQ2/DQ2 }\end{array}$ & $\begin{array}{c}\text { NSAID } \\
\text { +propranolol }\end{array}$ & No & $\begin{array}{l}\text { Full } \\
\text { recovery }\end{array}$ \\
\hline
\end{tabular}

NM, not mentioned; NSAID, non-steroidal anti-inflammatory drugs.

in viral antibodies to influenza, mumps, coxsackie, and adenovirus of four fold or more. Joasoo et al. ${ }^{16}$ have similarly found in a case control study in patients with thyrotoxicosis, that there was an increased frequency of antibodies to the influenza B virus. Sato ${ }^{17}$ had observed virus-like particles in the thyroid tissue of a patient with SAT which, judging by the particle size, corresponded to either influenza or mumps viruses. Finally, two recent cases reported the development of SAT after clinical infection with influenza. ${ }^{11,18}$ However, although these studies and observations are important, they nonetheless offer limited evidence for influenza infection in SAT. ${ }^{14}$ Hence, reports about the association of influenza vaccine with SAT should be considered a significant addition to the literature.

In conclusion, this is a rare case of SAT following influenza vaccine and adds to the evidence linking influenza with SAT. Physicians should be aware that SAT can follow the administration of influenza vaccines including those containing the (H1N1) pdm09 strain. Affected patients, especially individuals with an HLA B35 haplotype, might also show susceptibility to autoimmune disorders.

\section{References}

1. Catania P, Pela I. Vasculitis in a boy with ESRD following influenza vaccination. Vaccine 2010;28:877-8.

2. Liu PY, Shi ZY, Lee CH. Cutaneous vasculitis following influenza vaccination. Intern Med 2010;49:2187-8.

3. Shoamanesh A, Traboulsee A. Acute disseminated encephalomyelitis following influenza vaccination. Vaccine 2011;29:8182-5.

4. Maeda K, Idehara R. Acute disseminated encephalomyelitis following 2009 H1N1 influenza vaccination. Intern Med 2012;51:1931-3.

5. Hoshino T, Uchiyama Y, Ito E, et al. Simultaneous de- velopment of acute disseminated encephalomyelitis and Guillain-Barre syndrome associated with H1N1 09 influenza vaccination. Intern Med 2012;51:1595-8.

6. Schattner A. Consequence or coincidence? The occurrence, pathogenesis and significance of autoimmune manifestations after viral vaccines. Vaccine 2005;23:3876-86.

7. Girgis CM, Russo RR, Benson K. Subacute thyroiditis following the H1N1 vaccine. J Endocrinol Invest 2010; 33:506.

8. Yakushiji F. Subacute thyroiditis after seasonal influenza vaccination. Drugs Ther Stud 2011;1:33-4.

9. Hsiao JY, Hsin SC, Hsieh MC, et al. Subacute thyroiditis following influenza vaccine (Vaxigrip) in a young female. Kaohsiung J Med Sci 2006;22:297-300.

10. Hernan Martinez J, Corder E, Uzcategui M, et al. Subacute thyroiditis and dyserythropoesis after influenza vaccination suggesting immune dysregulation. Bol Assoc Med P R 2011;103:48-52.

11. Cunha BA, Berbari N. Subacute thyroiditis (de Quervain's) due to influenza A: presenting as fever of unknown origin (FUO). Heart Lung 2013;42:77-8.

12. Kojima M, Nakamura S, Oyama T, et al. Cellular composition of subacute thyroiditis. an immunohistochemical study of six cases. Pathol Res Pract 2002;198:833-7.

13. Engkakul P, Mahachoklertwattana P, Poomthavorn P. De Quervain thyroiditis in a young boy following handfoot-mouth disease. Eur J Pediatr 2011;170:527-9.

14. Desailloud R, Hober D. Viruses and thyroiditis: an update. Virol J 2009;6:5.

15. Volpe R, Row VV, Ezrin C. Circulating viral and thyroid antibodies in subacute thyroiditis. J Clin Endocrinol Metab 1967;27:1275-84.

16. Joasoo A, Robertson P, Murray IP. Viral antibodies in thyrotoxicosis. Lancet 1975;2:125.

17. Sato M. Virus-like particles in the follicular epithelium of the thyroid from a patient with subacute thyroiditis (De Quervain). Acta Pathol Jpn 1975;25:499-501.

18. Dimos G, Pappas G, Akritidis N. Subacute thyroiditis in the course of novel H1N1 influenza infection. Endocrine 2010;37:440-1. 